\title{
O DESENHO INFANTIL DE CRIANÇAS DE TRÊS ANOS E SUA ARTICULAÇÃO COM OS RUDIMENTOS DA ESCRITA
}

\author{
EL DIBUJO INFANTIL DE NIÑOS DE TRES AÑOS Y SU ARTICULACIÓN CON \\ LOS RUDIMENTOS DE LA ESCRITURA
}

\section{THE DRAWING OF 3-YEARS OLD CHILDREN AND THEIR ARTICULATION WITH THE RUDIMENTS OF WRITING}

\author{
Cristiane Moraes ESCUDEIRO ${ }^{1}$ \\ Eliza Maria BARBOSA ${ }^{2}$ \\ Janaína Cassiano SILVA ${ }^{3}$
}

RESUMO: Este artigo descreve e analisa a construção de uma sequência didática utilizada para assegurar o desenvolvimento do desenho do esquema corporal, realizada com crianças na faixa etária de três a quatro anos de idade, que frequentam uma escola de Educação Infantil da rede pública de Araraquara. Defendemos a perspectiva de que essa etapa da escolaridade básica embora não tenha como função precípua a consolidação do processo de alfabetização, pode oferecer-lhe uma contribuição original à medida que o concebemos como o resultado de um processo que articula os gestos, a linguagem oral, o desenho e a escrita, numa trajetória de construção coletiva e cultural. Os pressupostos da Psicologia Histórico-Cultural e da Pedagogia Histórico-Crítica subsidiam a discussão. Nessa abordagem teórica buscamos as referências para defender o desenho como uma das formas exclusivamente humanas de representação da realidade, tomando-o como conteúdo de ensino. Ao defendê-lo como conteúdo de ensino e ao construir uma sequência didática que permita seu progressivo desenvolvimento, reiteramos a concepção sobre a natureza humanizadora da educação escolar definida pela Pedagogia Histórico-Crítica. Os resultados da aplicação da sequencia de ensino indicam um avanço nas expressões gráficas das crianças e corroboram a defesa da Educação Infantil como contexto de consolidação, na contemporaneidade, das máximas possibilidades das crianças como seres genéricos.

PALAVRAS-CHAVE: Desenho. Educação infantil. Pedagogia Histórico-Crítica. Psicologia Histórico-Cultural. Alfabetização.

RESUMEN: Este artículo describe y analiza la elaboración de una secuencia didáctica utilizada para garantizar el desarrollo del dibujo del esquema corporal, realizada con niños de tres a cuatro años de edad, que frecuentan una escuela de Educación Infantil de la red de escuelas públicas de Araraquara (São Paulo-Brasil). Defendemos la perspectiva de que esa etapa de la escolaridad básica, aunque no tenga la función precipua de consolidación del proceso de alfabetización, puede ofrecerle al niño una contribución original a la medida que lo concebimos como el resultado de un proceso

\footnotetext{
${ }^{1}$ Professora de Educação Infantil da Rede Municipal de Araraquara. Mestre em Educação Escolar. Faculdade de Ciências e Letras - FCLAr/UNESP, Araraquara, Brasil. E-mail: crisescudeiro@yahoo.com.br.

${ }^{2}$ Professora Doutora em Educação. Departamento de Psicologia da Educação - Faculdade de Ciências e Letras - FCLAr/UNESP, Araraquara, Brasil. E-mail: eliza@ fclar.unesp.br.

3 Professora Doutora. Departamento de Psicologia - Universidade Federal de Goiás, IBIOTEC/UFG. Programa de Pós-Graduação em Educação, Catalão, Brasil. E-mail: janacassianos@gmail.com.
} 
que articula los gestos, el lenguaje oral, el dibujo y la escritura, en una trayectoria de construcción colectiva y cultural. Los principios de la Sicología Histórico-Cultural y de la Pedagogía Histórico-Crítica subsidian la discusión. En ese abordaje teórico buscamos las referencias para defender el dibujo como una de las formas exclusivamente humanas de representación de la realidad, tomándolo como contenido de enseñanza. Al defenderlo como contenido de enseñanza y al elaborar una secuencia didáctica que permita su progresivo desarrollo, reiteramos la concepción sobre la naturaleza humanizadora de la educación escolar definida por la Pedagogía HistóricoCrítica. Los resultados de la aplicación de la secuencia de la enseñanza indican un avance en las expresiones gráficas de los niños y corroboran la defensa de la Educación Infantil como contexto de consolidación, en la contemporaneidad, de las posibilidades máximas de los niños como seres genéricos.

PALABRAS CLAVE: Dibujo. Educación infantil. Pedagogía histórico-crítica. Sicología histórico-cultural. Alfabetización.

ABSTRACT: This article describes and analyzes the construction of a didactic sequence used to ensure the development of the body image, carried out with children aged three to four years old, who attend a public Early Childhood Education in Araraquara. We defend the point of view that this stage of basic education although does not have as main function consolidate the literacy process can offer a unique contribution to this process as we conceive it as the result of a process that articulates gestures, spoken language, drawing and writing, in a collective and cultural construction trajectory. The presuppositions of Cultural-Historical Psychology and Historical-Critical Pedagogy subsidize the discussion. Based on this approach, we seek references to defend the drawing as one of the exclusively human ways to represent reality, turning it as teaching significant content. To defend it as a teaching content and build a didactic sequence to allow its further development we reiterate the humanizing role of formal education as defined by Historical-Critical Pedagogy. The results of sequence execution indicate an advance in the graphic expressions of children and support the conception of early childhood education as a context of consolidation, in contemporary times, of the maximum possibilities of children as generic humans.

KEYWORDS: Drawing. Early childhood education. Historical-critical pedagogy. Cultural-historical psychology. Literacy.

\section{Introdução}

Este artigo trata do desenvolvimento da capacidade exclusivamente humana de representar a realidade natural e social por meio dos gestos, linguagem oral, desenho e escrita, com ênfase nessas duas últimas, concebendo a relação de continuidade entre elas como expressão de uma materialidade gráfico-visual. É nesse lugar que desenho e escrita, enquanto marcas sobre o papel se relacionam e, dada a complexidade de ambas as formas de representação, podemos refletir sobre uma necessária articulação entre a Educação Infantil e o processo de Alfabetização. 
Para tanto, apresentamos a experiência desenvolvida com crianças de três anos de idade de uma escola de Educação Infantil do Município de Araraquara-SP, realizada com o objetivo de assegurar-lhes o domínio da expressão da figura humana. As análises produzidas na segunda parte do artigo, sobre o processo de desenvolvimento da representação pelo desenho, apoiam-se no referencial teórico da Psicologia HistóricoCultural e, na Pedagogia Histórico-Crítica. Com base nos pressupostos e na análise dos resultados, referendamos a defesa de práticas intencionais como essenciais para o trabalho educativo na Educação Infantil.

O objetivo central do artigo é indicar uma sequência didática que se mostrou eficiente e produtiva, constatada pelos resultados observados nas análises e desenhos ilustrados. Por esses mesmo resultados, demonstramos que, embora a Educação Infantil não tenha como função assegurar integralmente os domínios exigidos no processo formal de alfabetização, ela contribui efetivamente para o desenvolvimento da relação entre fala, desenho e escrita na medida em que, já ao desenhar, as crianças desenham os conteúdos dos textos orais e escritos pelos quais transitam, incorporando as falas dos adultos e dos colegas. Para nós, tal relação configura-se em objeto privilegiado de ensino na Educação Infantil. Para os autores da Psicologia Histórico-Cultural, as práticas educativas dirigidas sistematicamente para a produção de conhecimentos novos com as crianças desde seus primeiros meses de vida, constituem a via exclusiva de humanização das mesmas e sua consolidação como seres pertencentes ao gênero humano ${ }^{4}$.

Sob tais princípios tem se reafirmado a especificidade da escola, em todas as suas etapas, incluindo a Educação Infantil. Segundo Saviani (2015, p.35) muito embora a educação não-escolar tenha sido historicamente a forma original de educação das novas gerações, na contemporaneidade, a educação escolar tornou-se a "forma principal e dominante da educação". Os estudos de Arce e Martins (2009), Martins (2012), Martins e Marsiglia (2015), Pasqualini (2015), Arce e Jacomeli (2012), Arce (2014), Barbosa et al. (2015), Barbosa e Silva (2013, 2015a), Silva (2008, 2013) entre outros, corroboram a defesa de uma concepção de Educação Infantil que tem produzido avanços, ao instituir um discurso teórico-metodológico que reconfigure as práticas educativas dirigidas às crianças, realizando suas "[...] máximas possibilidades de desenvolvimento". (MARTINS, 2009, p.93).

\footnotetext{
${ }^{4}$ Para a Psicologia histórico-cultural o gênero corresponde às características exclusivamente humanas não
} presentes no nascimento, que não resultam da herança biológica, mas forjam-se nas relações culturais. 
Martins (2009) nos lembra de que independentemente da faixa etária que atende, à escola cabe à função de transmitir a cultura para além das esferas cotidianas. Para isso, as práticas educativas escolares, além de assegurar que os conhecimentos científicos tornem-se presentes no ensino das crianças menores de seis anos, devem ocupar-se também em promover os conteúdos que incidem de modo direto no desenvolvimento das crianças, acrescentando-lhes novos hábitos e habilidades tais como: “[...] autocuidados; hábitos alimentares saudáveis; destreza psicomotora; acuidade perceptiva e sensorial; habilidades de comunicação significativa; identificação de emoções e sentimentos; vivência grupal; dentre outras." (MARTINS, 2009, p.95). Por sua vez, o ensino de conteúdos escolares, e incluímos entre eles o ensino de técnicas e recursos para o desenho e posteriormente à escrita, operam indiretamente sobre o desenvolvimento, contribuindo para a conversão de funções psicológicas elementares em superiores, ou seja, a aprendizagem de um conteúdo incide sobre a memória, percepção, atenção, linguagem, etc.

Saviani (2012) ao definir a natureza e a especificidade do trabalho educativo, nos diz que sua natureza é não-material, pois está ligada à produção de ideias, conceitos, hábitos, etc., e a sua especificidade se define pela transmissão do saber historicamente acumulado com o objetivo de produzir intencionalmente, em cada indivíduo da espécie humana, as capacidades socialmente desenvolvidas pelo conjunto dos homens, cujos resultados se encontram sintetizados na Arte, nas Ciências e na Filosofia. Nesse intento, o autor afirma que o objeto da educação exige, além da identificação dos elementos culturais que precisam ser ensinados às crianças, decidir sobre as melhores formas de ensiná-las. Para a escolha dos conteúdos, Saviani (2012, p.13) indica-nos a necessidade de privilegiar os conhecimentos clássicos entendendo-os como aquilo que se "[...] firmou como fundamental, como essencial".

Nesse artigo, apresentamos o desenvolvimento do desenho como conteúdo com uma importância em si mesmo, à medida que permite às crianças expressarem graficamente aquilo que sabem sobre os objetos e fenômenos, e ainda, com uma importância indireta sobre o desenvolvimento da linguagem em geral e da escrita em particular. Como indica Luria (1986, p.27), a consciência se produz pela capacidade do homem de "[...] sair dos limites do reflexo imediato sensorial da realidade, de sua capacidade de refletir o mundo em suas relações mais complexas e abstratas mais profundamente do que permite à percepção sensível". Ao desenhar e, mais tarde, ao escrever, as crianças registram ideias, sentimentos, conceitos sem nenhum apoio de 
elementos não verbais tais como, gestos, entonação, pausas e outros, presentes, por exemplo, na linguagem oral (LURIA, 1986).

Por sua vez, a sequência didática que passaremos a descrever, constituiu-se numa forma legítima de assegurar o desenvolvimento do conteúdo (desenho da figura humana) pelas crianças. A organização do espaço, materiais, procedimentos, com a devida mediação teórica, resultantes da experiência de que trata este texto, indica-nos que somente por meio de práticas intencionais e conscientes a escola possibilita às crianças a conversão das coisas imediatamente percebidas em objetivações humanas.

\section{Do desenho infantil aos rudimentos da escrita: contexto, percurso didático e considerações teóricas}

Na cidade de Araraquara/SP a Educação Infantil está organizada para atender as crianças na faixa etária de 0 a 2 anos nos Berçários, de 2 a 3 anos nas C.I (Classes Intermediárias), de 3 a 4 anos na $3^{\text {a }}$ etapa, de 4 a 5 anos na $4^{\text {a }}$ etapa e de 5 a 6 anos na $5^{\text {a }}$ etapa. Neste ano de 2016 encontram-se matriculadas, no total de 42 Centros de Educação e Recreação (CERs) do município, aproximadamente dez mil crianças, sendo 1.300 em média, as que estão na faixa etária de 3 a 4 anos.

Desde o ano de 2014, a Secretaria Municipal de Educação vem construindo, por meio do Programa Cresça e Apareça ${ }^{5}$, uma nova proposta curricular para a Educação Infantil, buscando subsídios teóricos nas contribuições dos autores da Psicologia histórico-cultural e da Pedagogia Histórico-Crítica. Dentre as diversas ações que convergem para a construção dessa nova proposta, estão as avaliações sobre o processo de ensino e aprendizagem das crianças que tem como objeto, no agrupamento de três a quatro anos ( $3^{\text {a }}$ etapa), o desenvolvimento do desenho. Essa avaliação não visa à promoção ou estratificação das crianças, mas a identificação dos avanços alcançados e as dificuldades persistentes.

No primeiro semestre de 2016, os professores da $3^{\text {a }}$ etapa receberam, pela primeira vez, a orientação para avaliar o nível de desenvolvimento do esquema corporal que os (as) alunos (as) conseguiam representar através do desenho. Tal avaliação será feita ao longo do ano, em duas fases: a primeira foi realizada no primeiro semestre,

${ }^{5} \mathrm{O}$ programa Cresça e Apareça oferece formação continuada aos professores e agentes educacionais que atuam na Educação Infantil da rede pública de Araraquara-SP. Desde o ano de 2014, os pressupostos da Pedagogia Histórico-Crítica subsidiam essas formações, bem como a construção de uma nova proposta curricular e pedagógica para a rede. Para mais informações ver: Barbosa e Silva (2015b). 
entre os meses de Março e Junho, e a segunda será aplicada no segundo semestre, entre os meses de Setembro e Novembro. Os desenhos e suas análises que apresentamos a seguir são das crianças da $3^{\text {a }}$ etapa do C.E.R. Rubens Cruz II, no bairro Selmi Dey, aplicada inicialmente aos (as) alunos (as) individualmente. Para uma melhor avaliação do desenvolvimento do desenho das crianças, fizemos essa primeira fase da avaliação em três momentos diferentes, mas em dias próximos. No $1^{\circ}$ momento, elas desenharam sem nenhum tipo de modelo ou elemento de inferência; no $2^{\circ}$ momento deveriam completar o rosto da imagem que continha apenas o corpo e no $3^{\circ}$ momento, a partir da imagem de uma cabeça, teriam que completar o corpo.

Realizamos esses três procedimentos, pois era necessário observar, inicialmente, quais crianças já desenhavam sem o auxílio de um modelo ou recurso mnemônico, mesmo sem terem, ainda, memorizado o esquema corporal como um todo e quais as que somente conseguiam fazer a representação da figura humana, utilizando um modelo como referência. O primeiro desenho, feito individualmente pelas crianças e sem auxilio externo, demonstrou que nenhuma das vinte e uma crianças conseguia desenhar o esquema corporal contendo: tronco, membros inferiores e superiores e a cabeça, sendo que cinco conseguiam esquematizar rudimentarmente o esquema corporal, isto é, apresentavam traços iniciais do que poderia ser uma das partes e apenas desenharam a cabeça, mas sem um corpo pré-definido. Assim, tínhamos quase a metade da sala, mais ou menos, em um determinado nível de desenvolvimento, enquanto a outra parte ainda precisava evoluir em sua representação figurativa.

Tendo essa avaliação inicial como referência para nortear o trabalho pedagógico ao longo do semestre, nos perguntamos: Por que seria importante para a criança aprender a desenhar o esquema corporal? O desenvolvimento do desenho teria alguma influência no processo de escrita? Qual seria a relação entre o desenvolvimento do desenho na faixa etária de três anos e o processo de alfabetização? Como fazer para que as crianças continuassem progredindo?

Muito embora não tenhamos a pretensão de esgotar as respostas às questões acima formuladas, buscamos a seguir pensar sobre as mesmas à luz das contribuições da Psicologia Histórico-Cultural considerando para isso o legado deixado por essa teoria a respeito de pensar o desenvolvimento das atividades especificamente humanas como atividades que devem se reproduzir em cada indivíduo em particular, como requisito para sua própria humanização. 
Se colocarmos um instrumento de desenho nas mãos de uma criança de mais ou menos um ano de idade, que está começando a andar e a explorar os objetos do ambiente podemos esperar dela duas reações: ou ela o colocará na boca ou, tendo observado a atividade de algum adulto ou mesmo de uma criança mais velha, escrevendo ou desenhando, tentará imitá-los, fazendo rabiscos. Nesse sentido, a atividade de desenhar, pelo simples fato de movimentar o corpo, além de ser uma experimentação, é uma fonte de prazer para a criança. Desenhar, antes de tudo, é algo que surge na infância como uma brincadeira da qual as crianças gostam e participam com bastante vontade.

Na Educação Infantil, por exemplo, as crianças estão sempre desenhando. Mas, é necessário que se desenhe com alguma finalidade? O professor deve interferir no desenho da criança ou isso tolheria sua imaginação? Se observarmos os desenhos das crianças menores de seis anos, podemos verificar que a maior parte de suas representações gráficas tem figuras do corpo humano, de animais, de casas, de árvores etc., isto é, de ilustrações do seu próprio cotidiano. No entanto, para que ela alcance o estágio mais desenvolvido, percorrerá um longo caminho, que se inicia com rabiscos, dando continuidade as primeiras garatujas, com linhas e formas, até que despontem imagens mais definidas.

As pesquisas de Vigotski (2007) realizadas com crianças menores de sete anos identificaram o caminho de desenvolvimento percorrido no que se refere ao desenho chegando até a escrita infantil. Nesse percurso, o autor nos aponta um processo que se divide em quatro estágios: o de gestos e signos visuais; o desenvolvimento do simbolismo no brinquedo; o desenvolvimento do simbolismo no desenho e por fim, o simbolismo na escrita. Nossas análises buscam aproximar-se desse percurso.

Sabendo que teríamos um período de três meses para demonstrar avanços nos desenhos antes da aplicação da segunda avaliação, traçamos uma sequência didática de atividades pedagógicas que se iniciaria com momentos mais coletivos, nos quais as crianças teriam que realizar tarefas, dentro e fora da sala de aula, ora com o auxílio de modelos, ora sozinhas. Começamos, então, a trabalhar músicas, danças, jogos e brincadeiras $^{6}$ que fizessem referência ao corpo humano. Por meio delas, desenvolvemse também conteúdos que incidem de modo direto sobre o desenvolvimento tais como, novos domínios motores, a capacidade de concentração, além da ampliação do

${ }^{6}$ As palavras em destaque indicam os procedimentos e/ou estratégias metodológicas que compõem a sequência didática apresentada nesse artigo. 
vocabulário, através da aprendizagem de novas palavras que definem as partes do esquema corporal. Essa primeira etapa durou mais ou menos um mês, e, junto com ela, iniciamos, a observação, a percepção e a comparação das características corporais das crianças do grupo, fazendo o uso de espelho e de manipulação de objetos (como o manuseio de bonecos).

Ressaltamos que, de acordo com Vigotski (2007), nessa fase, a linguagem gestual é predominante. Nesse momento, a criança está ampliando seu repertório linguístico e, ao mesmo tempo, começando a explorar cada vez mais os objetos ao seu redor, na tentativa de conhecer o nome das coisas e compreender a relação entre elas. $\mathrm{Na}$ faixa etária de três anos aproximadamente, observa-se nos desenhos o predomínio dos denominados "rabiscos", além do início das primeiras representações em forma de garatujas ou mais conhecidos como desenhos-girinos ou cabeça de batata, na qual a criança inclui algumas partes do rosto apenas, mas sem a composição de algo que indique um corpo, utilizando-se, geralmente, de linhas para traçar braços e pernas, com a ausência completa de mãos, pés e dedos.

Embora a criança pequena tenha um bom conhecimento sobre a figura humana e saiba apontar corretamente diversas partes do corpo, para desenhar a figura ela tem que descobrir que partes são usualmente incluídas e que partes são opcionais, saber como cada parte é desenhada, ser capaz de lembrar todas as partes enquanto desenha e fazê-lo na ordem correta, saber onde fica cada parte em relação a outras partes, e ser capaz de arrumar as partes em um conjunto no papel. Deve ainda ter um controle razoável sobre seus movimentos finos, de modo que os traços sigam por onde ela pretende. A tarefa aparentemente fácil de fazer um desenho esquemático da figura humana acaba envolvendo uma complexa coordenação de conhecimento e habilidade. (COX, 2007, p.43).

Se pararmos para refletir sobre essa citação, reconheceremos que desenhar é uma tarefa complexa para a criança de três anos, pois lhe exige certo planejamento e ideia previamente concebida. Tal complexidade origina-se justamente do fato dela não ter nem técnica e menos ainda, um repertório amplo (de imagens) que a auxilie em seu processo de desenvolvimento de representações figurativas. Por isso, os rabiscos encontrados nos desenhos iniciais de nossos (as) alunos (as) são, de fato, uma tentativa de colocar no papel os movimentos do corpo, ou seja, os gestos dos quais eles já se utilizavam antes mesmo de iniciar o domínio sobre a linguagem oral.

No desenho apresentado na figura 1, encontramos uma demonstração do que acabamos de afirmar. Do lado esquerdo, observamos um desenho contendo apenas 
"rabiscos". Ao representar seu próprio corpo, o aluno começou traçando duas linhas na parte de baixo da folha, passando em seguida a realizar movimentos aleatórios até preencher todo o papel. Nesse momento, podemos dizer que as crianças estão representam predominantemente, seus gestos. Mas não é apenas isto. Enquanto desenham, muitas delas se movimentam constantemente, como um todo. Algumas pulam, fazem pontos, sobem e descem com os braços, saindo do papel, levantam-se, ou seja, não são apenas as mãos que "trabalham", mas o corpo inteiro é explorado. Do lado direito, três meses depois, ao pedirmos à mesma criança para representar novamente seu corpo, visualizamos o início, mesmo que de forma simples, de algo que já começa a indicar formas, com movimentos agora mais circulares.

Figura 1 - A representação do esquema corporal em criança da $3^{\mathrm{a}}$ etapa

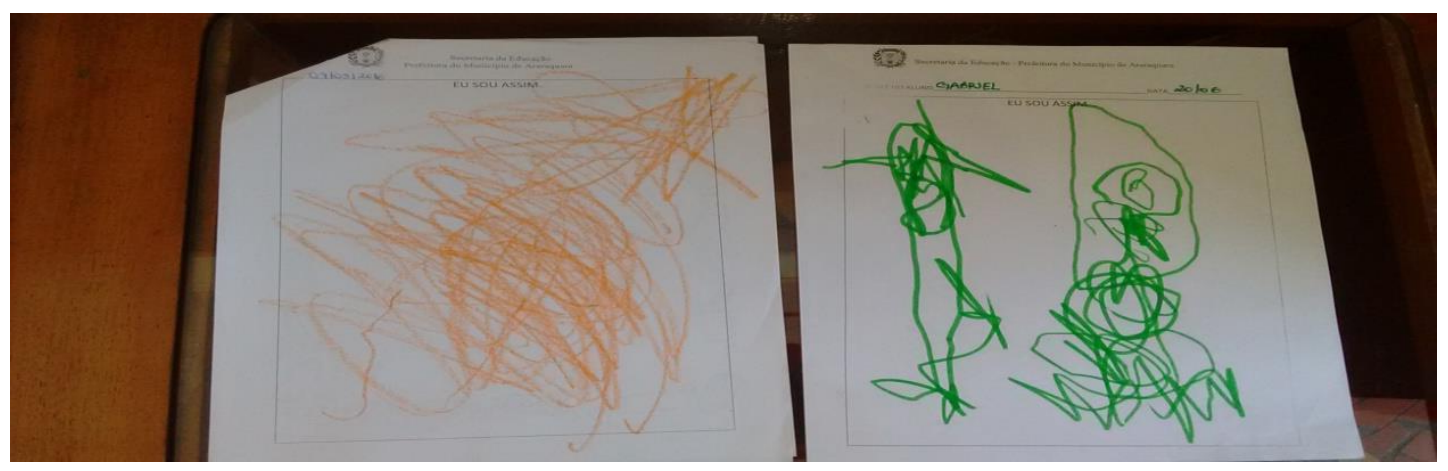

Fonte: Acervo recolhido e organizado pelas autoras.

De acordo com Vigotski (2007, p.129):

Em geral, tendemos a ver os primeiros rabiscos e desenhos das crianças mais como gestos do que como desenhos no verdadeiro sentido da palavra. Também tendemos a imputar ao mesmo tipo de fenômeno o fato, experimentalmente demonstrado, de as crianças, ao desenharem objetos complexos, não fazerem pelas suas partes componentes, e sim pelas suas qualidades gerais, como, por exemplo, a impressão do redondo etc.

Na Figura 2, do lado esquerdo, já encontramos o que Vigotski (2007, p.129) denominou, na citação aludida, como a "impressão do redondo". Na primeira avaliação, a aluna esquematiza o rosto, com suas partes, mas sem a presença de um corpo definido, apesar de fazer linhas, que se assemelham às pernas. Na segunda avaliação, ao se desenhar, ela já começa a retratar alguns aspectos da realidade e de suas próprias características físicas. Seu cabelo, por exemplo, como no desenho, é curto e bem 
cacheado. Em uma das atividades em sala de aula, ela representou sua família verbalizando que seu pai tinha o cabelo conforme ela desenhou: "Tia, meu pai tem o cabelo assim". No desenho também há uma boca com dentes. Além disso, como já entende que os olhos são feitos com círculos, já consegue utilizar pontos ("pingos") para representá-los.

Figura 2 - A representação de si de criança da $3{ }^{a}$ etapa

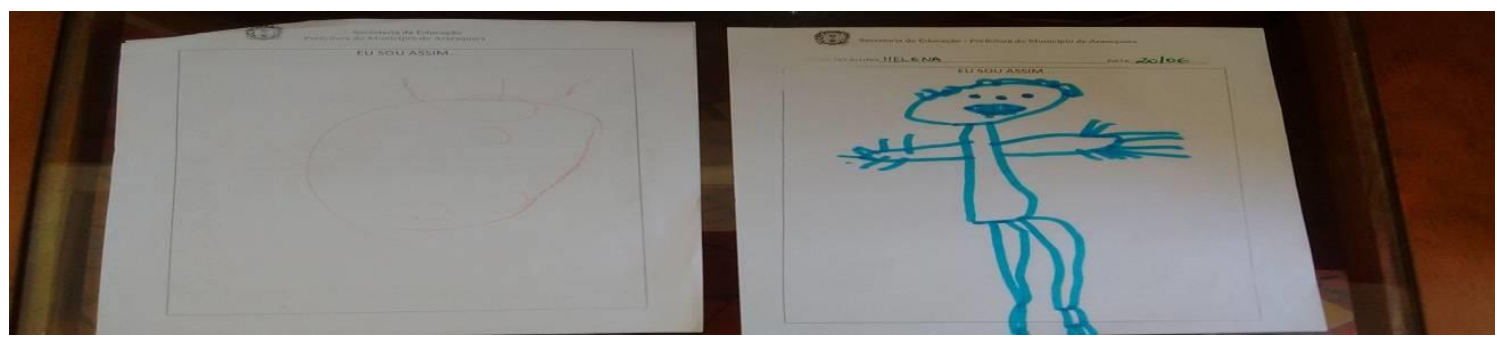

Fonte: Acervo recolhido e organizado pelas autoras.

Nessa direção, um fator importante, como destacou Vigotski (2007), que promove a passagem dos rabiscos às primeiras representações, são ações nas quais a criança vivencie brincadeiras de papéis sociais. Mas, qual seria a relação entre a brincadeira e o desenho? Para o autor, a manipulação de objetos ${ }^{7}$ é a principal via para conhecer a realidade. No entanto, na ausência de algum deles e diante da necessidade de incorporá-los à sua atividade lúdica, recorre a uma substituição, isto é, representa uma coisa com outra em seu lugar. É assim, por exemplo, que sabendo desse importante fator para o desenvolvimento infantil, nos utilizamos, na escola, de uma sala específica, denominada de "Multimeios", para a realização desses jogos protagonizados, por existir nela um repertório de brinquedos que sugerem às crianças brincar com objetos que podem representar a realidade e as relações entre as pessoas.

Para Vigotski (2007), os objetos cumprem uma função de indicação e substituição das coisas, pois existe, nesse instante, a criação de um simbolismo. Tal simbolismo com objetos é que, mais tarde, assumirá a função de signo. Ou seja, o que ora era brincadeira, gesto e movimento fora do papel, poderá ser representado, em um dado momento, "dentro" dele.

7 A Atividade Objetal Manipulatória é considerada por Elkonin (1987) a forma predominante de assimilação, pelas crianças, dos procedimentos de ação sobre os objetos elaborados socialmente. O contato com os objetos e sua exploração permite, além do domínio das técnicas de uso dos mesmos, a passagem da comunicação emocional à uma atividade colaborativa com os adultos que a ensinam essas técnicas. 
Para elas, alguns objetos podem, de pronto, denotar outros, substituindo-os e tornando-os seus signos; não é importante o grau de similaridade entre a coisa que se brinca e o objeto denotado. $\mathrm{O}$ mais importante é a utilização de alguns objetos como brinquedos e a possibilidade de executar, com eles, um gesto representativo [...] o próprio movimento da criança, seus próprios gestos, é que atribuem a função de signo ao objeto e lhe dão significado. (VIGOTSKI, 2007, p.129).

Nessa direção, após a primeira avaliação, além das brincadeiras de papéis sociais, passamos a trabalhar com alunos, para que desenvolvessem os rabiscos aleatórios e iniciassem o desenho das primeiras representações, com a utilização de diversos instrumentos e técnicas, além do uso de formas geométricas, que foram usadas como referência para a construção de um modelo, ou seja, começamos a desenhar a figura humana a partir de círculos, quadrados, triângulos e retângulos. Nesse momento, é importante destacar que os desenhos dados como modelo, devem ser produzidos de modo semelhante para que as crianças, aos poucos, observem um padrão representativo facilmente identificado mnemônicamente.

Uma criança de três anos é capaz de compreender a função representativa de uma construção com brinquedos, enquanto a criança de quatro anos dá nome às suas criações antes mesmo de começar a construí-las. Da mesma forma, notamos no desenho que a criança com três anos ainda não é consciente do significado simbólico do seu desenho, o que só será dominado completamente, por todas as crianças, em torno dos sete anos. (VIGOTSKI, 2007, p.134).

Como desenhar a figura humana não é uma tarefa fácil, pois exige a organização da estrutura do que se pretende construir, é importante que nesse momento a fala do professor direcione a ação da criança enquanto ela desenha, pois isso ajuda na orientação da representação figurativa, à medida que incentiva o (a) aluno (a) a "pensar" (ou lembrar daquilo que está presente em sua memória). Além disso, "tarefas" nas quais a criança precise completar as partes da figura humana, auxiliam no desenvolvimento da percepção do esquema corporal como um todo. Outro fator que influencia o desenho infantil é a colocação de interferências no papel para que a criança tenha como um ponto de partida, um objeto ou uma imagem para dar início às suas ilustrações. Assim, podemos, por exemplo, entregar uma folha contendo uma pipa como elemento de inferência para influenciar o desenho das mãos nos desenhos que ainda estavam ausentes. 
De acordo com Vigotski (2007, p.135) as crianças desenham aquilo que está em sua memória, desse modo elas "[...] não desenham o que veem, mas sim o que conhecem. Com muita frequência, os desenhos infantis não só não têm nada a ver com a percepção real do objeto como, muitas vezes, contradizem essa percepção". O autor nos esclarece que, nessa fase, a criança desenha como se estivesse narrando fatos. Ela faria isso, sobretudo, porque ainda não consegue visualizá-lo em seus aspectos mais complexos e gerais, então desenha o que percebe como essencial do objeto. Por isso, a cabeça humana pode ser um círculo com apenas dois olhos e o restante do corpo pode ser indicado como duas linhas paralelas, sem o restante de suas partes. Quem olha, sabe que é a figura de um corpo humano, mas reconhece a ausência do restante de sua estrutura.

\begin{abstract}
Vemos, assim, que o desenho é uma linguagem gráfica que surge tendo por base a linguagem verbal. Nesse sentido, os esquemas que caracterizam os primeiros desenhos infantis lembram conceitos verbais que comunicam somente os aspectos essenciais dos objetos, esses fatos nos fornecem os elementos para passarmos a interpretar o desenho das crianças como um estágio preliminar no desenvolvimento da escrita. (VIGOTSKI, 2007, p.136).
\end{abstract}

É nessa medida que o simbolismo do brinquedo segue em direção ao simbolismo do desenho e este, mais tarde, percorrerá o caminho até o simbolismo da escrita. Desse modo, a escrita surgiria, segundo Vigotski (2007), quando a criança percebesse que pode desenhar, além dos objetos de suas brincadeiras, agora, também, sua própria fala. Nesse momento, a intensificação do trabalho com o nome das crianças, bem como o som de suas letras, ajuda na percepção de seus desenhos, pois à medida que a representação do seu esquema corporal aparece cada vez mais completo e complexo, aparecem, de forma bem elementar, letras e números, como se fossem a finalização dos desenhos. O que antes era expressão da fala, como dizer o nome, a letra inicial e contar, agora já são representados.

$\mathrm{Na}$ figura 3, podemos observar, entre o primeiro e segundo momento da avaliação, os avanços alcançados pela aluna quanto ao seu desenho. Na figura 4, percebemos que agora ela já escreve letras, quando finaliza suas atividades. No entanto, para que conseguisse fazer tal procedimento, foi necessário que seu desenho chegasse a um estágio de evolução mais complexo no qual ela tentasse representar, além dele, outras coisas que estavam sendo ensinadas no dia-a-dia da sala de aula, como o nome próprio e as letras do alfabeto. É como se a criança "assinasse", o que já é capaz de 
desenhar sozinha. A escrita de letras, aos poucos, tem aparecido nas atividades de outras crianças que se encontram no mesmo nível de desenvolvimento ou em um estágio até mais avançado. Isso nos indica que aprender a desenhar a figura humana é uma etapa importante no processo de escrita. As letras aparecem como parte da composição desenhada, vão ser lidas como um tipo de letra-desenho, não com o valor de escrita.

Do ponto de vista pedagógico, essa transição deve ser propiciada pelo deslocamento da atividade da criança do desenhar coisas para desenhar a fala [...] o desenvolvimento da escrita nas crianças se dá, conforme já foi descrito, pelo deslocamento do desenho de coisas para o desenho de palavras. (VIGOTSKI, 2007, p.140).

Figura 3 - A concepção da criança da $3^{\text {a }}$ etapa acerca de si (1)

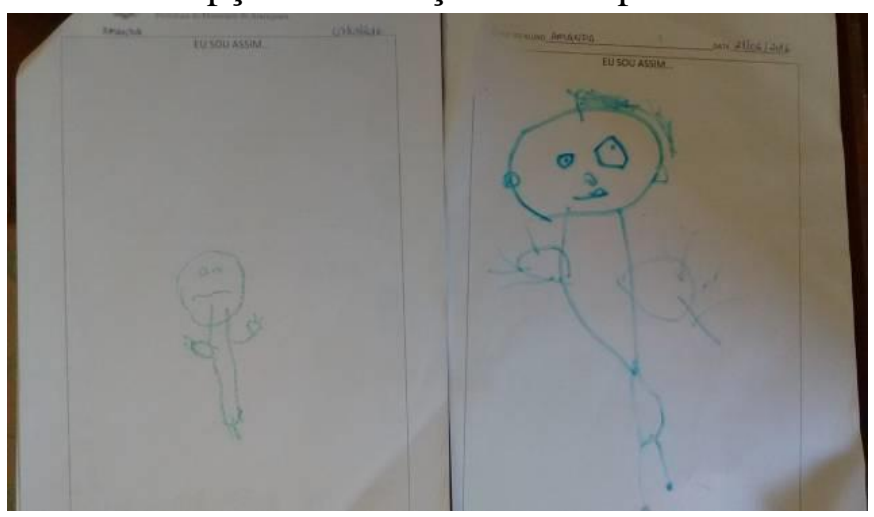

Fonte: Acervo recolhido e organizado pelas autoras.

Figura 4 - Final de atividade da criança da $3^{\text {a }}$ etapa (2)

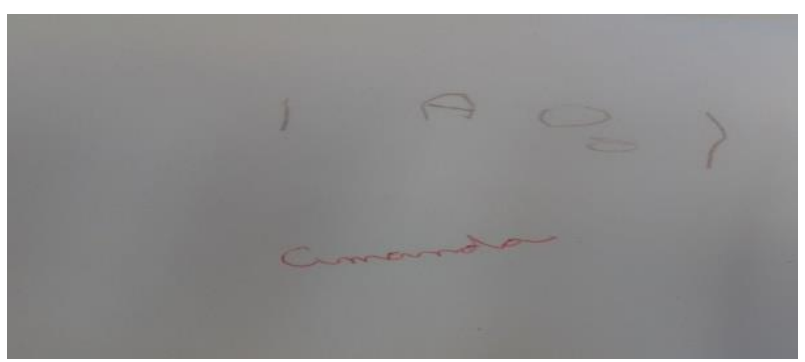

Fonte: Acervo recolhido e organizado pelas autoras.

A essa altura cabe-nos perguntar: Como a criança passa dos rabiscos aleatórios a desenhos que quase expressam fielmente a realidade? Isso acontece de forma espontânea ou são necessárias intervenções? De acordo com Cox (2007), as mudanças nas representações gráficas não acontecem de forma natural ou espontânea e alguns aspectos como representar o volume, tamanho e localização interferem e promovem alterações nos desenhos infantis. Para o autor, desenhar não é uma atividade tão simples 
como parece e a criança pode passar um longo tempo nos "rabiscos" porque, além de ser algo que já tem domínio (e é descontraído), não lhe impõe a tarefa de construir uma determinada figura.

Outro aspecto ressaltado por Cox (2007) e bastante relevante para analisarmos os desenhos infantis é que a criança, ao iniciar a fase das primeiras formas humanas, desenha o corpo sem uma divisão definida das partes. Por exemplo: pode desenhar um círculo para fazer a cabeça, colocando dois olhos para definir o rosto, e linhas saindo dela, representando as pernas e os braços. No entanto, apesar da ausência de algumas partes do corpo isto, não necessariamente, significa que não estejam presentes. Segundo Cox (2007, p.39), “[...] As crianças talvez chamem o segmento principal de sua figura de cabeça, mesmo que ela represente mais do que isso".

Como a criança desenha aquilo que sabe (ou tem na memória) e não o que vê, como já ressaltaram Cox (2007) e Vigotski (2009), é necessário que o professor desenhe para ela utilizando predominantemente o mesmo modelo e as mesmas formas de representação. Isso não significa que a mesma fará uma cópia fiel. Muito pelo contrário. Tomando uma imagem como referência, a criança é capaz de criar a sua própria representação, colocando em seu desenho aspectos de sua habilidade e personalidade. Nessa direção, o trabalho do professor destaca-se na medida em que ele direciona a ação do (a) aluno (a), com o objetivo de ampliar seu repertório e promover o desenvolvimento figurativo.

Vigotski (2009) definiu em quatro fases os estágios de desenvolvimento do esquema corporal. Para efeito de análise das últimas produções das crianças que queremos discutir nesse artigo, faremos uma breve referência apenas ao primeiro e segundo estágios ${ }^{8}$. O autor explica que no primeiro estágio a criança desenha como se estivesse enumerando as partes do corpo ou, em outras palavras, como uma "narração gráfica" daquilo que está em sua memória e se pretende representar. Nessa fase, ela desenha aquilo que acredita ser o mais essencial no objeto e não o que observa nele. Assim, pode acrescentar em seu desenho alguma característica que seja excessiva ou ocultar-lhe algum traço ou forma que não seja primordial naquele momento. Já o segundo estágio

${ }^{8}$ Para maiores conhecimentos sobre os estágios de desenvolvimento do esquema corporal ver: Vigotski (2009). 
[...] é denominado de estágio do surgimento do sentimento de forma e da linha. Na criança, desperta aos poucos a necessidade não apenas de enumerar aspectos concretos do objeto, mas também de transmitir as inter-relações formais das partes. Nesse segundo estágio de desenvolvimento do desenho infantil percebemos, por um lado, a mistura da representação formal com a esquemática- são ainda desenhos esquema- e, por outro, encontramos rudimentos da representação parecida com a realidade. Esse estágio não pode ser é claro, nitidamente delimitado pelo precedente. No entanto, ele se caracteriza por um número bem maior de detalhes, por uma disposição mais verossímil de partes isoladas do objeto: ocultações impressionantes como a do torso não são mais percebidas; todo o desenho aproxima-se da aparência real do objeto. (VIGOTSKI, 2009, p.108).

Nas figuras 5 e 6, podemos perceber a evolução do desenho infantil da mesma criança, a partir da citação aludida, seguindo os apontamentos de Vigotski (2009) sobre o primeiro e segundo estágio. $\mathrm{O}$ desenho à esquerda resulta do primeiro e segundo momento da primeira fase da avaliação realizada no primeiro semestre. Já o segundo desenho, à direita, é produto de uma atividade do início das aulas, no mês de Agosto, com o tema sobre o "Dia dos pais". Nele, a criança teria que representar a figura paterna. Se olharmos a imagem, verificaremos que ela se parece realmente com uma figura masculina, com sobrancelhas mais grossas e um bigode.

A criança muito pequena, que está começando a fazer desenhos figurativos, consegue talvez fazer uma linha razoavelmente reta ou uma forma fechada toscamente circular. Além de ter esse repertório limitado, ela pode também se ver restrita pela dificuldade em lembrar as diversas partes que compõem a coisa que quer desenhar e em ordená-las na correta posição espacial no papel. (COX, 2007, p.27).

Figura 5 - Representação de si de criança da $3^{\mathrm{a}}$ etapa (1)

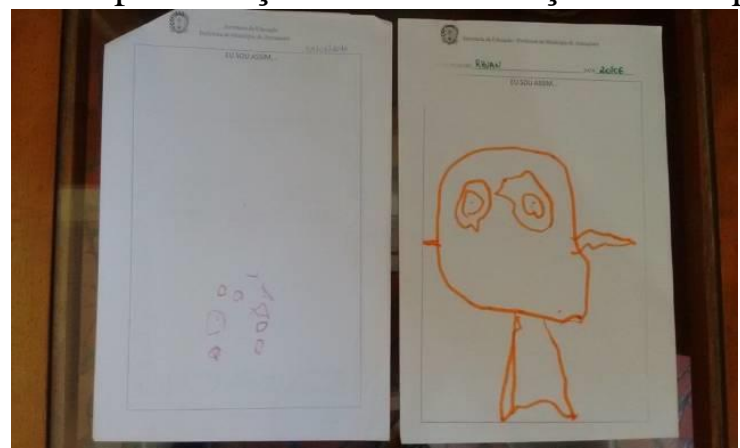

Fonte: Acervo recolhido e organizado pelas autoras. 
Figura 6 - Representação de si de criança da $3^{\mathrm{a}}$ etapa (2)

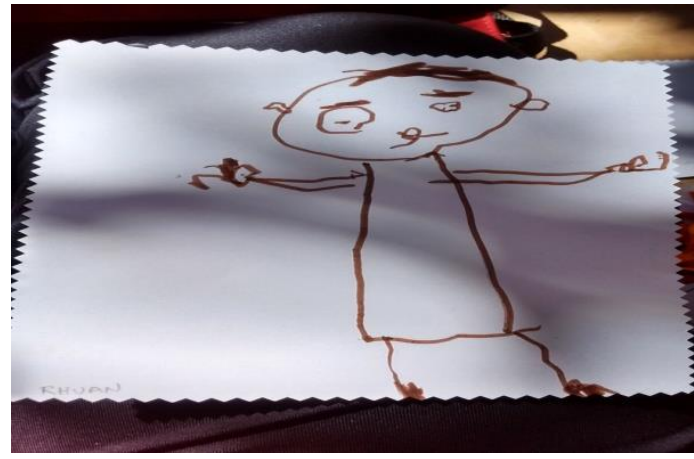

Fonte: Acervo recolhido e organizado pelas autoras.

A sequência didática utilizada com as crianças se legitima na medida em que os resultados obtidos indicam que quinze crianças já conseguiam esquematizar de forma mais definida sua imagem corporal, pois além de conter todas as partes do esquema, ainda acrescentam traços que lhe são próprios, tais como: cor e textura do cabelo, cor de pele, adereços, etc. Cinco delas passaram a representar o corpo humano com a ajuda de um modelo ou sob nossa orientação e apenas uma avançou de modo insuficiente, entretanto trata-se de uma criança que tem uma frequência irregular. Em outro momento desse trabalho, à luz da discussão de Saviani (2012) sobre o objeto da educação, lembramos que definir a melhor forma de ensinar é uma decisão que cabe aos docentes tomar. Indicamos a seguir, de modo sintético, as ações que compuseram nossa sequência de atividades e procedimentos: $1^{\mathrm{a}}$ trabalhar com músicas, danças $\mathrm{e}$ brincadeiras que façam referência às partes do corpo humano; $2^{\mathrm{a}}$ observação e percepção do próprio corpo, com o uso de espelho; $3^{\text {a }}$ brincadeira de papéis sociais e manipulação de objetos por meio de rodas de exploração das partes do corpo de bonecas; $4^{\mathrm{a}}$ desenhos com diferentes instrumentos e técnicas, com e sem modelo; $5^{\mathrm{a}}$ uso de formas geométricas para a representação de partes da figura humana; $6^{\mathbf{a}}$ atividades para completar as partes do corpo; $7^{\mathrm{a}}$ desenho com intervenção de objetos e imagens; $8^{\mathrm{a}}$ atividades com a escrita do nome e o som de letras.

\section{Considerações finais}

Concluímos que o desenho e o uso de diferentes técnicas que façam as crianças se desenvolverem é um conteúdo clássico na Educação Infantil, não exclusivamente das crianças de três a quatro anos, devendo ser, como outros conteúdos, trabalhados de 
modo intencional pelos professores. $\mathrm{O}$ desenho ou a tarefa de desenhar não pode se limitar a um procedimento que ocupe as "horas vagas" da rotina ou apenas em circunstâncias espontâneas, pois, como demonstramos, ele estrutura-se, articuladamente às demais formas predominantes de representação humana: os gestos, a linguagem oral e a escrita, pelas condições externas da vida social e histórica, onde afinal forjam-se os processos psíquicos superiores de cada novo ser do gênero humano.

Reiteramos assim a defesa de práticas intencionais na Educação Infantil, comprometidas com a formação integral das crianças e com a ampliação máxima de seus conhecimentos sobre a realidade, pois, como nos lembra Vygotsky (2009), as crianças desenham de memória, desenham o que sabem sobre as coisas e aquilo que lhes parece mais essencial nelas. Dessa análise podemos inferir que, se o desenvolvimento do desenho condiciona-se pelo grau de conhecimento que as crianças têm sobre o mundo natural e humano, também as demais apropriações como: leitura, escrita, técnicas de criação, apreciação estética, cálculos entre outras, forjam-se em condições reais de vida, por meio de um processo ativo de intercâmbio com outros homens, tendo a escola como instituição formal de transmissão dessas apropriações.

\section{REFERÊNCIAS}

ARCE, A. (Org.). O trabalho pedagógico com crianças de até três anos. Campinas: Alínea, 2014.

ARCE, A.; JACOMELI, M. R. M. (Org.). Educação infantil versus educação escolar: entre a (des) escolarização e a precarização do trabalho pedagógico nas salas de aula. Campinas: Autores Associados, 2012.

ARCE, A.; MARTINS, L (Org.). Ensinando aos pequenos de zero a três anos. Campinas: Editora Alínea, 2009.

BARBOSA, E. M.; SILVA, J. C. Aprendizagem versus ensino: falsa oposição ou uma nova didática pré-escolar. Poiésis, Catalão, v.11, n.2, p.114-132, jul./dez. 2013.

BARBOSA, E. M.; SILVA, J. C. Entre a psicologia e a pedagogia: reflexões sobre o desenvolvimento infantil e o conhecimento escolar à luz da Teoria Histórico-Cultural. Revista Ibero Americana de Estudos em Educação, Araraquara, v.10, n.4, p.12971318, 2015a.

BARBOSA, E. M.; SILVA, J. C. O programa Cresça e Apareça e a construção de uma proposta crítica para a educação da Infância em Araraquara/SP. In: $1^{\circ}$ CONGRESSO 
PEDAGOGIA HISTÓRICO-CRÍTICA: Educação e Desenvolvimento Humano, 2015b, Bauru. Anais... Bauru: Faculdade de Ciência, 2015a. p.1624-1636. Disponível em: <http://www2.unesp.br\#!/phcbauru2015.>. Acesso em: 10 set. 2016.

BARBOSA, E. M. et al. O desenvolvimento de conceitos novos pelas crianças préescolares no âmbito da relação entre a pedagogia e a psicologia da educação. In: MOURA, J. G.; ROSSI, M. A. L. A iniciação científica nas licenciaturas: a pesquisa como prática de formação de professores. Goiânia: Gráfica UFG, 2015. p.97-118.

COX, M. Desenho da criança. Tradução de E. Ferreira. 3.ed. São Paulo: Martins Fontes, 2007 (Psicologia e Pedagogia).

ELKONIN, D. Sobre el problema de la periodización del desarrollo psíquico en la infancia. In: DAVIDOV, V.; SHUARE, M. (Org.). La psicología evolutiva y pedagógica en la URSS (antología). Moscou: Progresso, 1987. p.125-142.

LURIA, A. R. Pensamento e linguagem: as últimas conferências de Luria. Tradução de D. M. Lichtenstein e M. Corso. Porto Alegre: Artes Médicas, 1986.

MARTINS, L. M. O desenvolvimento do psiquismo e a educação escolar: contribuições à luz da psicologia histórico-cultural e da pedagogia histórico-crítica. Interfaces (Botucatu), Botucatu, v.16, n.40, jan./mar. 2012.

MARTINS, L. M. O ensino e o desenvolvimento de zero a três anos. In: ARCE, A.; MARTINS, L. M. (Org.). Ensinando aos pequenos de zero a três anos. Campinas: Editora Alínea, 2009. p.93-123.

MARTINS, L. M.; MARSIGLIA, A. C. G. As perspectivas construtivistas e histórico-crítica sobre o desenvolvimento da escrita. Campinas: Autores Associados, 2015.

PASQUALINI, J. C. Objetivos do ensino da educação infantil à luz da perspectiva histórico-crítica e histórico-cultural. Revista Germinal: Marxismo e Educação em Debate, Salvador, v.7, n.1, p.200-209, jun. 2015.

SAVIANI, D. O conceito dialético de mediação na pedagogia histórico-crítica em intermediação com a psicologia histórico-cultural. Revista Germinal: Marxismo e Educação em Debate, Salvador, v.7, n.1, p.26-43, jun. 2015.

SAVIANI, D. Pedagogia histórico-crítica: primeiras aproximações. 11.ed. Campinas: Autores Associados, 2012.

SILVA, J. C. A apropriação da psicologia histórico-cultural na educação infantil brasileira: análise de teses e documentos oficiais no período de 2000 a 2009. 2013. 278 f. Tese (Doutorado em Educação) - Programa de Pós-graduação em Educação, Universidade Federal de São Carlos, São Carlos, 2013.

SILVA, J. C. Práticas educativas: a relação entre cuidar e educar e a promoção do desenvolvimento infantil à luz da Psicologia Histórico-Cultural. 2008. $214 \mathrm{f}$. 
Dissertação (Mestrado em Educação Escolar) - Faculdade de Filosofia, Ciências e Letras, Universidade Estadual Paulista, Araraquara, 2008.

VIGOTSKI, L. S. A formação social da mente: o desenvolvimento dos processos psicológicos superiores. Tradução de J. Cipolla Neto, L. S. M. Barreto e D. C. Afeche. 7.ed. São Paulo: Martins Fontes, 2007.

VIGOTSKI, L. S. Imaginação e criação na infância: ensaio psicológico (livro para professores). Tradução de Z. Prestes. São Paulo: Ática, 2009.

\section{Como referenciar este artigo}

ESCUDEIRO, Cristiane Moraes; BARBOSA, Eliza Maria; SILVA, Janaína Cassiano. O desenho infantil de crianças de três anos e sua articulação com os rudimentos da escrita. Revista Ibero-Americana de Estudos em Educação, Araraquara, v.11, n. esp. 4, p. 2287-2305, 2016. Disponível em: <https://dx.doi.org/10.21723/riaee.v11.esp4.9194>. E-ISSN: 1982-5587

Submetido em: setembro/2016

Aprovado em: novembro/2016 